\title{
Decision Support Framework for Inspection and Maintenance; A Focus on Bridges using Post- Tensioning Tendons
}

\author{
Mahdy Taeby ${ }^{1}$ and Armin B Mehrabi ${ }^{2 *}$ \\ ${ }^{1}$ Research Assistant, Florida International University, Miami, Florida, USA \\ ${ }^{2}$ Associate Professor, Florida International University, Miami, Florida, US
}

*Corresponding author: Armin B Mehrabi, Associate Professor, Florida International University, Miami, Florida, USA.

Received Date: September 05, 2019

Published Date: September 12, 2019

\begin{abstract}
Aging and decay of transportation facilities, and the higher long-term cost of passive maintenance has led to the need for development of proactive management systems for bridge maintenance, repair and rehabilitation. This paper proposes a framework for Bridge Decision Support Framework (BDSF) as a form of proactive asset management system. A BDSF allows the asset manager to perform economic analyses on a bridge in order to establish priorities and make preliminary selection of preservation, repair or rehabilitation options. Among various bridge systems, segmental bridges using internal and external post-tensioning have faced great challenges due to issues related to the durability of the posttensioning tendons. Although some reserve capacity has been designed into these bridges, failure of tendons can have profound effect in the safety and structural integrity. These experiences have stressed the need for a proactive and predictive BDSF. A major component of such system is the ability to accurately plan inspection and condition assessment of the bridge, and to provide appropriate mitigation strategies preventing major damages to progress beyond manageable levels. Employing BDSF allows consideration of a variety of rehabilitation scenarios and strategies under different criteria when different decision makers are involved. The BDSF proposed in this paper considers a bridge as a system comprising of subsystems, each with distinct structural role and performance. Special emphasis is placed on post-tensioning tendons as critical subsystem. This paper attempts to identify subsystems for a post-tensioned bridge, their position in the structural integrity of system, respective properties and deterioration potentials.
\end{abstract}

Keywords: Bridges; Post-tensioned bridges; Post-tensioning tendons; Reliability; Risk-based maintenance; Condition assessment; Maintenance; Decision Making; Rehabilitation; Corrosion; Deterioration.

Notation

\begin{tabular}{|c|c|}
\hline$C_{M}$ & Moment Capacity \\
\hline$C_{T}$ & Tension Capacity \\
\hline$D_{M}$ & Moment Demand \\
\hline$D L_{B o x}$ & Dead load due to precast concrete box section \\
\hline$D L_{\text {Nonbox }}$ & Dead load due to concrete overlay, wearing surface, and side barriers \\
\hline$F_{C}$ & Normal tensile force \\
\hline$F_{T}$ & Actual compressive strength of concrete \\
\hline$f_{c}$ & Flexural limit state function \\
\hline$g(x . t)$ & Live load based on lane load \\
\hline$L L_{\text {Lane }}$ & Live load based on tandem load \\
\hline$L L_{\text {Tandem }}$ & Live load based on truck load \\
\hline$L L_{\text {Truck }}$ & Probability of flexural failure \\
\hline$P_{f}$ & Vector of influential parameters and variables \\
\hline$x$ & Reliability index \\
\hline$\beta$ &
\end{tabular}




\begin{tabular}{|c|c|}
\hline$\beta_{\text {target }}$ & Target reliability index \\
\hline$\beta(x . t)$ & Time-variant reliability index \\
\hline$\varphi$ & Cumulative distribution function of the standard normal distribution \\
\hline
\end{tabular}

The Above symbols are used in Figure 3.

\section{Introduction}

As important links within the overall transportation infrastructure, all bridges experience deterioration during their service life, and bridges using post-tensioning tendons, hereafter referenced as PT bridges, are not an exception. In fact, PT bridges have experienced alarmingly fast deterioration causing major concerns among bridges owners. Figure 1 shows a dissected tendon with incomplete grouting and severe corrosion of steel strands, a finding that applies to many contemporary bridges. Addressing bridge deterioration requires regular inspections, maintenance and repair actions targeted at improving the condition of the bridge and bridge elements and reducing the risk of failure. Because damage in PT tendons is in most cases not readily evident (FDOT) and the high costs associated with maintenance operations, the proper decision support framework for maintenance activities is needed to avoid (a) unexpected structural failures, and (b) unnecessary spending on maintenance and repair activities. Aging and decay of transportation facilities, and the higher long-term cost of passive maintenance has led to the need for development of proactive management systems for bridge maintenance, repair and rehabilitation. A framework for Bridge Decision Support Framework (BDSF) is proposed here as a form of proactive asset management system.

Innovation in bridge maintenance and rehabilitation is the key to the health and wellness of bridges as a valuable national asset. A major component of maintenance and rehabilitation is the ability to accurately plan inspection and condition assessment of the bridge, and to provide appropriate mitigation strategies [1]. Employing a decision support framework is common in maintenance management since it can satisfy the needs of planning and assessment while at the same time has the ability to carry a variety of rehabilitation scenarios and strategies under different criteria when different decision makers are involved [2]. This paper attempts to investigate the application of a reliability-based maintenance decision making for PT bridges. A framework for decision support is devised for a general PT bridge in basic design phase and includes several modules under multiple tasks. This framework can be customized for each bridge with respect to bridge characteristics. This framework is applicable to all types of bridges, however, some of the modules in this framework are developed further using practical approaches for specific PT-type bridges. The proposed methodology attempts to take advantage of timedependent variation of bridge reliability based on deterioration models to represent an effective and practical framework. Through implementation of adaptive modules structural simulation can be updated and made more accurate. The framework takes advantage of life-cycle-cost analysis and risk assessment process for effective and meaningful decision making for maintenance.

\section{Problem Statement}

Highway bridges deteriorate over time and require implementation of inspection programs for detection of damage and indication of deterioration to allow on-time and effective repair and maintenance actions. Accordingly, the asset managers frequently face the following questions;

1. What is the current condition of the bridge?

2. How could the effect of aging on the condition of the bridge be predicted?

3. How could the bridge safety be considered in decision making?

4. What are the possible scenarios in case of bridge deterioration?

5. What are the risks associated with each scenario and corresponding costs?

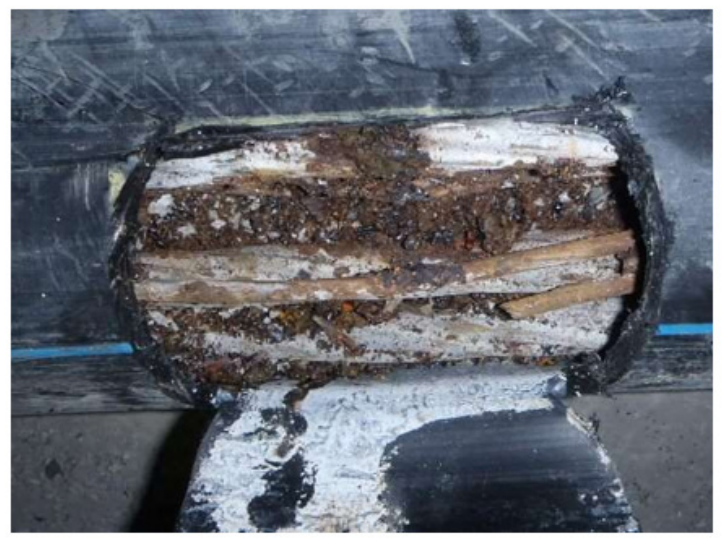

Figure 1: An example of deteriorated tendon in post-tensioned bridges.

Although abovementioned questions are general and open to all types of bridges, for PT bridges, response to the questions, from engineering point of view, needs more elaboration due to complications and uncertainties associated with damage types. Damage in PT tendons can be manifested as damage to corrosion protective barriers or corrosion of main tension elements. These damages in turn can be a result of a variety of caused including but not limited to workmanship, material deficiencies, presence of voids and moisture in grouted ducts, presence of contaminants in the material, exposure to external and internal invasive environment, temperature effects, presence of dissimilar material and formation of microcells, and other circumstances that may accelerate the deterioration process. Decision support framework for Maintenance of PT bridges assigns five tasks and corresponding 
modules to tackle asset managers concerns with reliance on engineering methodology to achieve the goal for each task.

\section{Background}

Many investigations have been carried out to identify failure mechanisms and their causes for PT bridges in order to prevent bridge collapse and improve public safety. However, a comprehensive and inclusive approach for decision making on health monitoring and maintenance of PT bridges is lacking. Most of available literature on the subject addresses corrosion of tendons and corresponding loss of their force [3-5], as well as selection of applicable nondestructive testing (NDT) methods for different types of PT bridges [6-8]. Very few investigations have been carried out on the effect of damages to PT tendons on the overall performance of deteriorating structures, and fewer have considered these effects based on a unified reliability-based analysis according to their probability of occurrences and associated risk/cost. The framework of system reliability and probabilistic assessment of element and system deterioration was developed for bridges by experts such as Frangopol and associates [9,10], Nowak and Collins [11]. Others [12-14] have spent some efforts for introducing deterioration models for PT bridges. Most recently, Pillai RG [15] published his work in structural reliability analysis of PT bridges. His work focused on electrochemical characterization of PT systems and proposed models for tension capacity of PT tendons with voids and exposed to environmental conditions. He conducted a timevariant structural reliability analysis on the developed models for PT bridges.

\section{An Overview of the Proposed Bridge Decision Support Framework}

Figure 2 shows a schematic depicting the bridge decision support framework that includes five major tasks, which includes;

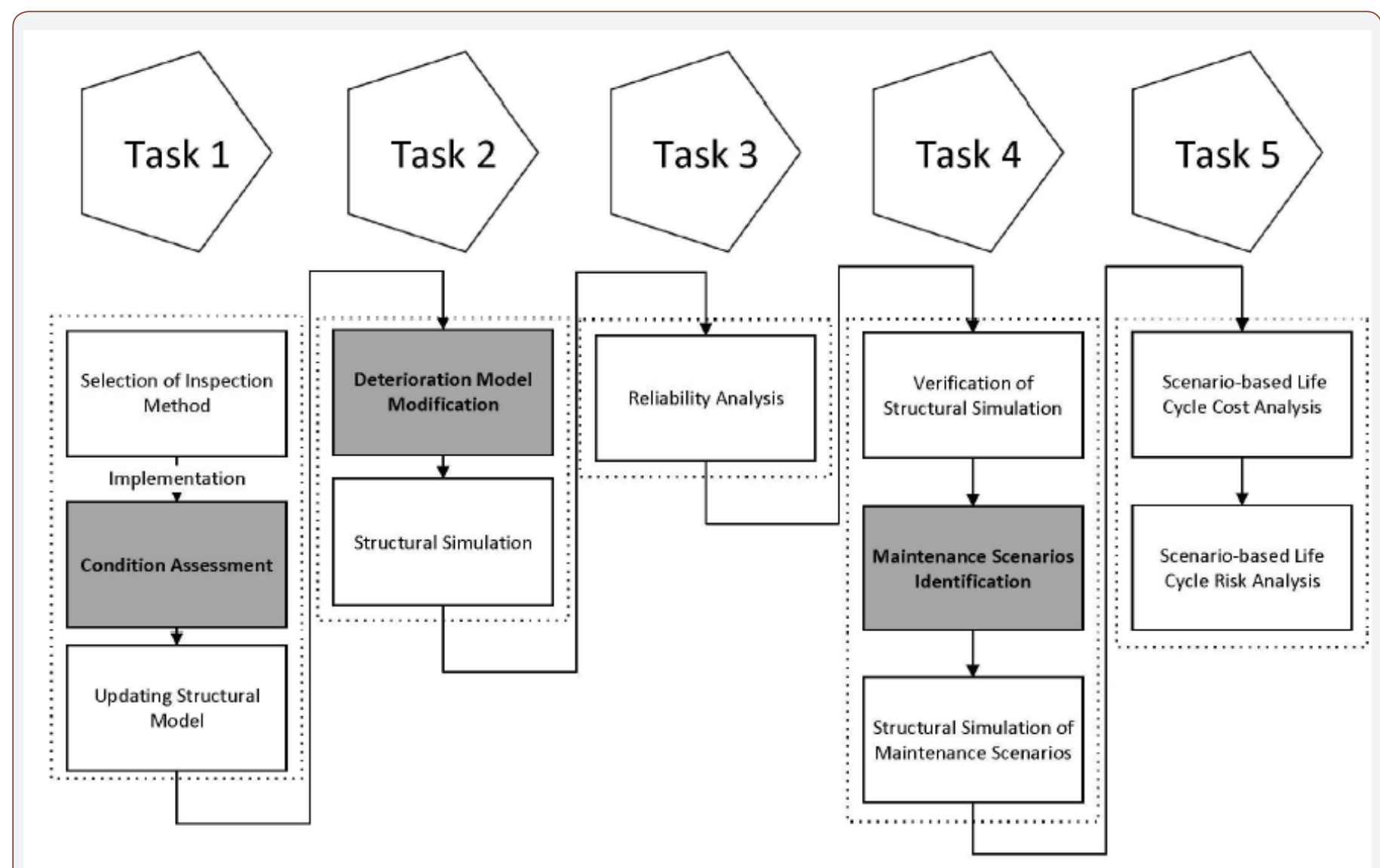

Figure 2: Bridge Decision Support Framework for PT bridges (Shaded modules require further development, and the rest require customization).

Task 1- Determine the current condition of the bridge using inspection methods.

Task 2- Evaluate the effect of aging on the condition of the bridge.

Task 3- Structural reliability analysis and governing limit states

Task 4- Identification of maintenance scenarios and corresponding effect on bridge reliability.

Task 5- Risk and life cycle cost analysis for proposed scenarios
Each task has been designed to address corresponding concerns by the asset managers and contains one or more modules. Overall, two groups of modules can be identified. The modules included in the first group. i.e., condition assessment, deterioration models and maintenance scenarios identification, depend directly on lifetime formulation of post-tensioned tendons. These modules require further development and offer opportunity of contribution for adding to the existing body of knowledge. Second group includes general and common modules providing for the application of the first group. Therefore, customization is needed in these modules 
based on the results of the first group and available techniques. Figure 2 illustrates the two groups of modules as discussed and the overall framework for decision making for PT bridges.

\section{Time-Dependent Reliability of Post-Tensioned (PT) Tendons}

Time-dependent Reliability of Post-Tesioning (PT) Tendons is the hardcore of BDSF. The framework proposed by Pillai [15] for time-variant flexural reliability of post-tensioned (PT) bridges is modified in order to make it more practical and compatible with second and third tasks of the BDSF. IN addition to developing deterioration model for resistance capacity of the tendons, reliability of the structure (system) including structural components need to be calculated. The steps for carrying out a reliability analysis using deterioration models are described in the following (Figure 3).

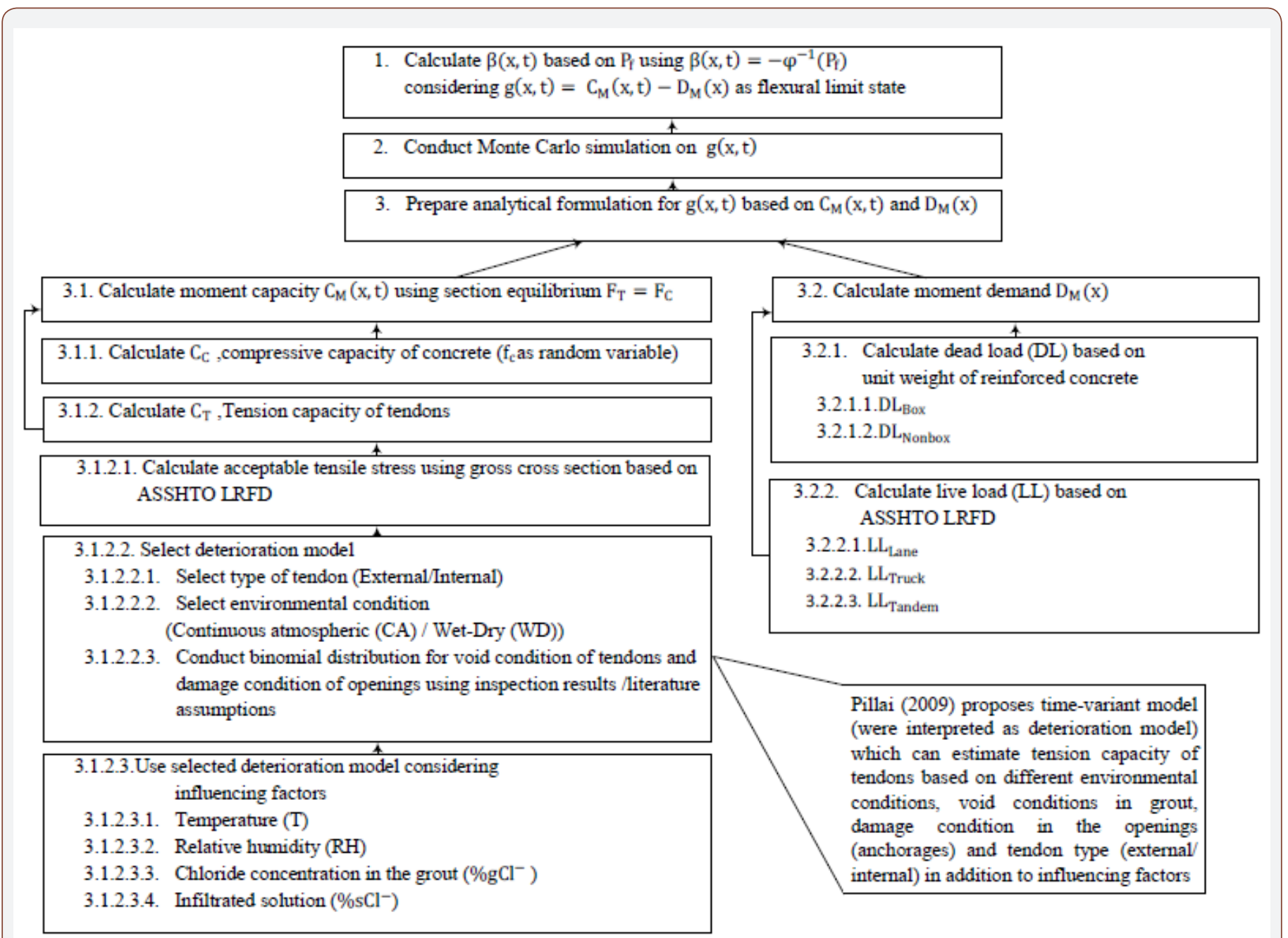

Figure 3: Time-dependent Reliability Analysis Flowchart for Post-Tensioned (PT) Bridges.

Most conventional reliability analyses have used the terminology of resistance (R) and load (Q). Here, the terminology employed by Pillai [15], that is, the term capacity (C) instead of resistance and demand (D) instead of load, are used that fits better to the complex case of post-tensioned bridges. Accordingly, a generalized reliability index, $\beta$, can be considered as a quantitative performance index for the safety of the structural systems. If we choose the moment as the defining load effect, then, the term $\beta$ can be defined based on the probability that the moment demand, $D_{M^{\prime}}$, equals or exceeds the corresponding moment capacity, $C_{M^{*}}$. In this case, the term $\beta$ denotes as flexural reliability index. Based on structural reliability techniques and probabilistic models for $D_{M}$ and $C_{M}$, a framework to assess the time-variant flexural reliability index, $\beta(x, t)$, of deteriorating PT bridges can be introduced. The vector $\mathrm{x}$ indicates various parameters and random variables (i.e., the tension capacity, $C_{T}$, of strands, the void and damage conditions of tendons, environmental conditions, and the external loading, geometrical, material, and structural characteristics of the bridge) influencing $D_{M}$ and $C_{M}$; and tindicates the exposure time (or the age of a PT bridge).

Procedure and steps for time variant reliability analysis for PT bridges is illustrated in the flowchart in Figure 3. It should be noted that:

1. Monte Carlo simulation is used to calculate probability of failure, and based on the probability of failure, reliability index $\beta(x, t)$ is calculated.

2. Flexural moment is used here as the critical load effect. The scheme can be adjusted to represent other load effects. 
3. Flexural limit state is defined as $g(x, t)=C_{M}(x, t)-$ $D_{M}(x)$ which considers only moment capacity as time variant parameter, and $g(x, t)<0$ represents flexural failure.

4. Analytical formulation of $C_{M}$ and $D_{M}$ not only needs mean values but also corresponding coefficient of variance (COV) of random variables, usually not available in codes and standards. We can use other reliability references such as Nowak and Collins [11] in order to complete the required data and complete the analysis. Mean value for random variables, except those variable related to deterioration model, are available in codes and standards, e.g., ASSHTO LRFD [16] bridge design specification.

5. Environmental condition factors influence selection of deterioration model of tendons which periodic wet-dry condition plays key role in this selection.

6. Influencing factors include temperature, relative humidity, chloride concentration in grout, chloride content in the air humidity and in infiltrated solution, involve in deterioration model as independent random variables.

7. Most importantly, deterioration model allows us to calculate corresponding time of interception between predicted reliability index and minimum acceptable threshold reliability index in order to plan for maintenance of PT Bridges and predict lifetime of all maintenance scenarios for tendons (Figure 3).

\section{Conclusion}

This paper proposes a framework for decision making on maintenance of post-tensioned (PT) bridges. The framework listed eleven modules and their interrelations aimed at assessment of current condition, prediction of future condition and ability to evaluate required maintenance scenarios for PT bridge, when tradeoff of cost and reliability is a concern. The framework is applicable to all types of bridges at basic level. For specific applications and quantification for practical purposes, some modules need further development and contribution to the body of existing knowledge. Modules required for completing the decisionmaking process were identified in this work, and a flowchart/ procedure was developed in order to tackle the knowledge gap, and to provide clarification and practical interpretation for otherwise vague concepts offered in very few literature available in this area. The estimation of reliability index for PT bridges is a complex process since the bridge is subjected to various structural and environmental loading conditions. A such, this paper also proposes a procedure and sequence for reliability analysis to address complexities due to exposure of post-tensioned bridges to a variety of structural, environmental, and deterioration conditions. This paper has also offered an opportunity for discussion on the timevariant moment capacity of the bridge system influenced by the capacity of tendons at the presence of void, damage, and various environmental conditions. The proposed framework can contribute to development of detailed approach to reliability-based decision making for complex structures such as PT bridges. Implementation of activities in this framework can facilitate on-time decision making for the type of maintenance activities and scenarios through determination of time-variable reliability of the structure, as well as by the way of updating of the reliability of the bridge taking into account the maintenance efforts and inspection results.

\section{Acknowledgement}

This paper represents a portion of doctoral study by the first author at Civil and Environmental Engineering Department of the Florida International University. The opinions and conclusion expressed in this paper are those of the authors.

\section{Conflict of Interest}

No conflict of interest.

\section{References}

1. Yehia S, Abudayyeh O, Fazal I, Randolph D (2008) A decision support system for concrete bridge deck maintenance. Advances in Engineering Software 39(3): 202-210.

2. Meridian Environmental Technology (2003) Development of a Maintenance Decision Support System (DSS) \& nbsp \&nbsp Federal Highway Administration (FHWA) and South Dakota Department of Transportation (SDDOT), Washington DC, USA.

3. American Concrete Institute (2014) Report on Corrosion of Prestressing Steels ACI-222.2R. American Concrete Institute (ACI), Farmington Hills, MI, USA.

4. Lau K (2016) Corrosion of post-tension tendons with deficient grout Florida Department of Transportation (FDOT). Tallahassee, FL, USA.

5. Lau K, Lasa I (2016) Corrosion of prestress and post-tension reinforcedconcrete bridges. Corrosion of Steel in Concrete Structures, A. Poursaee, ed., Woodhead Publishing, Cambridge, England, pp. 37-57.

6. Cullington DW, MacNeil D, Paulson P, Elliott J (2001) Continuous acoustic monitoring of grouted post-tensioned concrete bridges. NDT and E International 34(2): 95-105.

7. Krause M, Milmann B, Mielentz F, Streicher D, Redmer B, et al. (2008) Ultrasonic Imaging Methods for Investigation of Post-tensioned Concrete Structures: A Study of Interfaces at Artificial Grouting Faults and Its Verification. J Nondestruct Eval 27(1): 67-82.

8. Streicher D, Algernon D, Westmann J, Behrens M, Wiggenhauser H (2006) Automated NDE of post-tensioned concrete bridges using imaging echo methods. Proceedings of the 9th European Conference on NDT, Citeseer, pp. 25-29.

9. Frangopol DM, Estes AC (1997) Lifetime Bridge Maintenance Strategies Based on System Reliability. Structural Engineering International 7(3): 193-198.

10. Frangopol DM, Enright MP, Estes AC (1999) Integration of maintenance, repair, and replacement decisions in bridge management based on reliability, optimization, and life- cycle cost. Presentations from the 8th International Bridge Management Conference, Denver, Colo, Citeseer, pp. 26-28.

11. Nowak AS, Collins KR (2000) Reliability of Structures. McGraw-Hill, New York, NY, USA.

12. Cavell DG, Waldron P (2001) A residual strength model for deteriorating post- tensioned concrete bridges. Computers and Structures 79(4): 361373.

13. Tanaka Y, Kawano H, Watanabe H, Kimura T (2001) Chloride-induced deterioration and its influence on load carrying capacity of posttensioned concrete bridges. Third int. conf. concrete under severe conditions-Environment and loading, Citeseer, pp. 495-502.

14. Sancharoen P, Kato Y, Uomoto T (2008) Probability-Based Maintenance Planning for RC Structures Attacked by Chloride. Journal of Advanced Concrete Technology 6(3): 481-495. 
15. Pillai Gopalakrishnan R (2009) Electrochemical characterization and time-variant structural reliability assessment of post-tensioned, segmental concrete bridges. Texas A\&M, USA .
16. AASHTO (2017) LRFD bridge design specifications, 8th Ed. Washington DC, USA. 